\title{
Synthesis and degradation of poly- $\beta$-hydroxybutyrate in a sequencing batch biofilm reactor
}

\author{
Regina Nogueira *, Cláudia Alves, Maria Matos, António G. Brito \\ IBB - Institute for Biotechnology and Bioengineering, Centre of Biological Engineering, University of Minho, Campus de Gualtar, 4710-057 Braga, Portugal
}

\section{A R T I C L E I N F O}

\section{Article history:}

Received 14 July 2008

Received in revised form 31 October 2008

Accepted 11 November 2008

Available online 23 December 2008

\section{Keywords:}

Poly- $\beta$-hydroxybutyrate (PHB)

Sequencing batch biofilm reactor (SBBR)

Nitrogen removal

\begin{abstract}
A B S T R A C T
The aim of this work was the study of poly- $\beta$-hydroxybutyrate (PHB) formation and degradation in a sequencing batch biofilm reactor (SBBR). The SBBR was operated in cycles comprising three individual phases: mixed fill, aeration and draw. A synthetic substrate solution with acetate and ammonium was used.

PHB was formed during the aeration phase immediately after acetate depletion, and was subsequently consumed for biomass growth, owing to the high oxygen concentration in the reactor. It was observed a combination of suspended and biofilm growth in the SBBR with predominance of the fixed form of biomass (506 Cmmol and $2102 \mathrm{Cmmol}$, respectively). Maximum PHB fraction of suspended biomass $(0.13 \mathrm{Cmol} / \mathrm{Cmol})$ was considerably higher than that of biofilm $(0.01 \mathrm{Cmol} / \mathrm{Cmol})$. This may possibly be explained by a combination of two factors: lower mass transfer limitation of acetate and higher fraction of heterotrophs in suspended biomass compared to the ones of biofilm.
\end{abstract}

(c) 2008 Elsevier Ltd. All rights reserved.

\section{Introduction}

In wastewater treatment biological reactors are utilized to remove nutrients from the water in order to decrease negative effects on receiving water bodies. Usually, the biological treatment consists of several subsequent process steps, either occurring continuously in separate reactor volumes, or discontinuously in one single volume. The latter type, known as sequential batch reactors (SBR), are distinguished by their adaptability to varying conditions, since individual treatment phases can be easily modified, exchanged, added or removed. They are able to remove carbon, nitrogen and phosphorus in one single unit under properly controlled conditions (Brito et al., 2006; Rodrigues et al., 2001; Wilderer et al., 2001).

The characteristic feature of their operation is that the microorganisms in their biomass are exposed to continuous periodic changes of the environment, namely to varying liquid volumes and substrate concentrations (donors and receivers of electrons). When confronted with such interchanging periods of excessive substrate ("feast period") and insufficient substrate ("famine period"), the bacterial populations adopt specific survival strategies (Salehizadeh and van Loosdrecht, 2004). In particular, they often accumulate and set aside organic carbon as internal polymers such as glycogen or polyhydroxyalcanoates (PHA) (Karahan et al., 2008).

\footnotetext{
* Corresponding author. Tel.: +351253 604414; fax: +351253678986

E-mail address: regina@deb.uminho.pt (R. Nogueira).
}

The most frequent and abundant of these reserve polymers is poly$\beta$-hydroxybutyrate (PHB), which belongs to the PHA group.

The metabolism of PHB has been treated in various studies (Beun et al., 2000a,b, 2002), which indicate that it is stored by certain bacterial species when the uptake of substrate is higher than the conversion capacity of the assimilating process. The quantity of substrate, which is not directly used in the growing process, is then used in the synthesis of PHB. However, when the external substrate is depleted PHB is used in turn as a source of carbon and energy. Hence, through the use of PHB, certain bacterial species achieve a balanced growth even in dynamic substrate conditions, which allows them to utilize the external substrate more efficiently (Beun et al., 2000a; Krishna and van Loosdrecht, 1999; Majone et al., 1999) and ultimately out-compete other species within the system (Salehizadeh and van Loosdrecht, 2004).

While such storage phenomena are well studied for suspended biomass systems, as for example activated sludge SBRs, they are still poorly documented in literature for systems using biofilms, such as the sequencing batch biofilm reactor (SBBR) (Beun et al., 2001). Nevertheless, they do play an important role in the optimization of operating strategies, which holds particularly true for multiple and interlinked degradation pathways, such as the nitrogen and carbon removal by biological nitrification and denitrification. Therefore, the aim of this work was to study the PHB formation and degradation in a SBBR performing nitrogen removal in order to give new insights into the relevant biological processes and their internal relations. 


\section{Methods}

\subsection{Experimental set-up}

A SBBR with a working volume of $28 \mathrm{~L}$ was operated with a constant cycle time of $5 \mathrm{~h}$, a volume exchange ratio of $0.36 \mathrm{~L} / \mathrm{L}$ and a resulting hydraulic retention time (HRT) of $14 \mathrm{~h}$. The duration of the individual operating phases was: 115 min mixed fill, 165 min aeration and 20 min draw. The reactor was operated with a solids retention time (SRT) of 12.5 days. During the aeration phase airflow of $27 \mathrm{~L} / \mathrm{min}$ was applied through membrane diffusers, causing the reactor contents including the carrier bed to circulate. The dissolved oxygen (DO) was monitored continuously with a dissolved oxygen meter YSI, model 5000. The SBBR was operated at $20 \pm 1{ }^{\circ} \mathrm{C}$ and $\mathrm{pH} 7.5 \pm 0.1$.

The biofilm was formed on a new type of polyethylene support, developed by Universidade do Minho and consisting of hollow, star-shaped, carriers with $17 \mathrm{~mm}$ external diameter and a height of $10 \mathrm{~mm}$. The bed formed by these carriers had a specific surface area of $407 \mathrm{~m}^{2} / \mathrm{m}^{3}$, an average porosity of 0.74 and occupied $47 \%$ of the reactor volume.

\subsection{Substrate}

The composition of the synthetic substrate solution was: $643 \mathrm{mg} / \mathrm{L} \mathrm{NaCH}{ }_{3} \mathrm{COO} \cdot 3 \mathrm{H}_{2} \mathrm{O}, 130 \mathrm{mg} / \mathrm{L} \mathrm{NH}_{4} \mathrm{Cl}, 210 \mathrm{mg} / \mathrm{L} \mathrm{NaHCO}{ }_{3}$, $44 \mathrm{mg} / \mathrm{L} \mathrm{KH}_{2} \mathrm{PO}_{4}$, and $1 \mathrm{~mL} / \mathrm{L}$ of a trace element solution in accordance with Vishniac and Santer (1957). The carbon to nitrogen $(\mathrm{C} / \mathrm{N})$ ratio of the synthetic substrate solution was 3.3.

\subsection{Analysis}

Grab samples were taken and analyzed for ammonium, nitrite and nitrate according to standard methods. Acetate was analyzed using a high performance liquid chromatography (HPLC) system. PHB content of suspended biomass and biofilm (external and internal) was measured by gas chromatography (GC) using the method developed by Smolders et al. (1994). The ratio between PHB and active biomass without $\mathrm{PHB}\left(f_{\mathrm{PHB}}\right)$, was calculated according to Beun et al. (2002).

In situ hybridization of cells in the biofilm was performed with fluorescently labelled rRNA-targeted oligonucleotide probes according to the method of Manz et al. (1992). First the samples were hybridized with a EUB338 probe set (EUB338-I, EUB338-II, EUB338-III) designed to target almost all bacteria (Daims et al., 2001). Then, within this domain, the beta-subclasses of Proteobacteria was labelled with the respective group specific probes Bet42a and Gam42a (Manz et al., 1992). Within the beta-subclasses, in turn, the ammonia-oxidizing bacteria (AOB) were detected using the Nso1225 probe, which are specific for all ammonia-oxidizers in the beta-subclass Proteobacteria (Mobarry et al., 1996); The following probes were used to detect nitrite-oxidizing bacteria (NOB): (i) Nit3, which is complementary to a sequence region of all Nitrobacter species (Wagner et al., 1996); (ii) Ntspa662, specific for the genus Nitrospira (Daims et al., 2001). For detection of the different probe-targeted bacteria, simultaneous hybridizations were performed with Cy3 labelled specific probes and the FLUOS (Interactiva, Ulm, Germany) labelled bacterial probe set. Fluorescence signals were recorded with a LSM 510 confocal laser scanning microscope (Zeiss, Germany) equipped with HeNe laser (543 nm) or Ar laser (488 nm) for detection of Cy3 or FLUOS, respectively.

\subsection{Calculations}

Mass balance calculations were based on an assumed elemental composition of $\mathrm{CH}_{1.8} \mathrm{O}_{0.5} \mathrm{~N}_{0.2}$ for $1 \mathrm{Cmol}$ biomass (Beun et al., 2002).
The carbon consumption of hereotrophic growth was calculated based on the observed ammonium consumption and a biomass formation per mole of acetic acid of $0.40 \mathrm{Cmol} / \mathrm{Cmol}$ (Beun et al., 2000 b). Stoichiometric considerations for energy production lead to the following ratios of acetate consumption with respect to nitrate, nitrite, and oxygen: $1.25 \mathrm{Cmol}$ acetate $/ \mathrm{mol} \mathrm{NO}_{3}^{-}, 0.5 \mathrm{Cmol}$ acetate $/ \mathrm{mol} \mathrm{NO}_{2}^{-}$and $1 \mathrm{Cmol}$ acetate $/ \mathrm{mol} \mathrm{O}_{2}$, respectively. Oxygen transfer from the exterior into the liquid phase was considered negligible.

Ammonium ion consumption of the nitrification was estimated either from the nitrite or nitrate concentration in the case of incomplete or complete nitrification, respectively, at the end of the aeration phase. It was assumed that nitrification is performed by ammonium and nitrite-oxidizing bacteria with a biomass formation yield of $0.057 \mathrm{Cmol} / \mathrm{mol} \mathrm{NH}_{4}^{+}$and $0.034 \mathrm{Cmol} / \mathrm{mol} \mathrm{NO} \mathrm{NO}_{2}^{-}$, respectively (Henze et al., 1995).

The quantity of PHB in the biomass was expressed as:

$\% \mathrm{PHB}=\frac{\mathrm{PHB}}{\mathrm{PHB}+\mathrm{X}} \times 100(\mathrm{~g} / \mathrm{g})$

with $\mathrm{X}$ being the active biomass which is defined as organic material without PHB.

The active biomass' fraction of PHB was calculated as follows:

$f_{\mathrm{PHB}}=\frac{\% \mathrm{PHB}}{100-\% \mathrm{PHB}} \times \frac{M_{\mathrm{W}}^{\mathrm{X}}}{M_{\mathrm{W}}^{\mathrm{PHB}}}(\mathrm{Cmol} / \mathrm{Cmol})$

with $M_{\mathrm{W}}^{\mathrm{X}}$ and $M_{\mathrm{W}}^{\mathrm{PHB}}$ being the molecular weight of active biomass $(24.6 \mathrm{~g} / \mathrm{Cmol})$ and of PHB $(21.5 \mathrm{~g} / \mathrm{Cmol})$, respectively.

The parameters of PHB degradation kinetics (order and constant rate) were determined with the Aquasim software (Reichert, 1994).

\section{Results and discussion}

The SBBR was operated continuously for about one year before any detailed measurements were made. By then, a constant biomass dry weight in the reactor had established and nitrogen and carbon time profiles during consecutive cycles were reproducible. At the selected HRT, biomass in the reactor was present both in suspension (506 Cmmol or 20\%) and as biofilm (2102 $\mathrm{Cmmol}$ or $80 \%$ ). Biofilm was distributed between the external (18\%) and internal (62\%) surfaces of the carriers.

\subsection{PHB formation and degradation processes}

Formation and accumulation of PHB was observed both in suspended biomass and in biofilm. Fig. 1 depicts the PHB biomass ratio $\left(f_{\mathrm{PHB}}\right)$ of suspended biomass and biofilm (internal and external) and the acetate concentration in the bulk liquid observed during a SBBR cycle. During the mixed fill phase, $f_{\mathrm{PHB}}$ of the suspended biomass was practically constant, while a slight PHB accumulation was detected mainly in the external biofilm in close contact with the bulk liquid. The discontinuation of feed addition and simultaneous oxygen supply (aeration phase) induced a linear decrease of acetate and a linear increase of $f_{\mathrm{PHB}}$, both in suspended biomass and in the biofilm, indicating a zero order rate for acetate uptake and PHB formation. After acetate depletion in the bulk liquid, PHB was degraded at a decreasing rate until in both kinds of biomass the initial value was reached again.

According to these results, PHB was accumulated considerably stronger in suspended biomass than in biofilm: the maximum $f_{\mathrm{PHB}}$ of suspended biomass (observed at $125 \mathrm{~min}$ ) was, at least, a factor of ten times higher than the one of biofilm (Fig. 1). Considering the amounts of suspended biomass and biofilm in the reactor presented above, the experimental results indicate that of the total PHB stored $(113.9 \mathrm{Cmmol})$, as much as $79 \%$ were accumulated in 


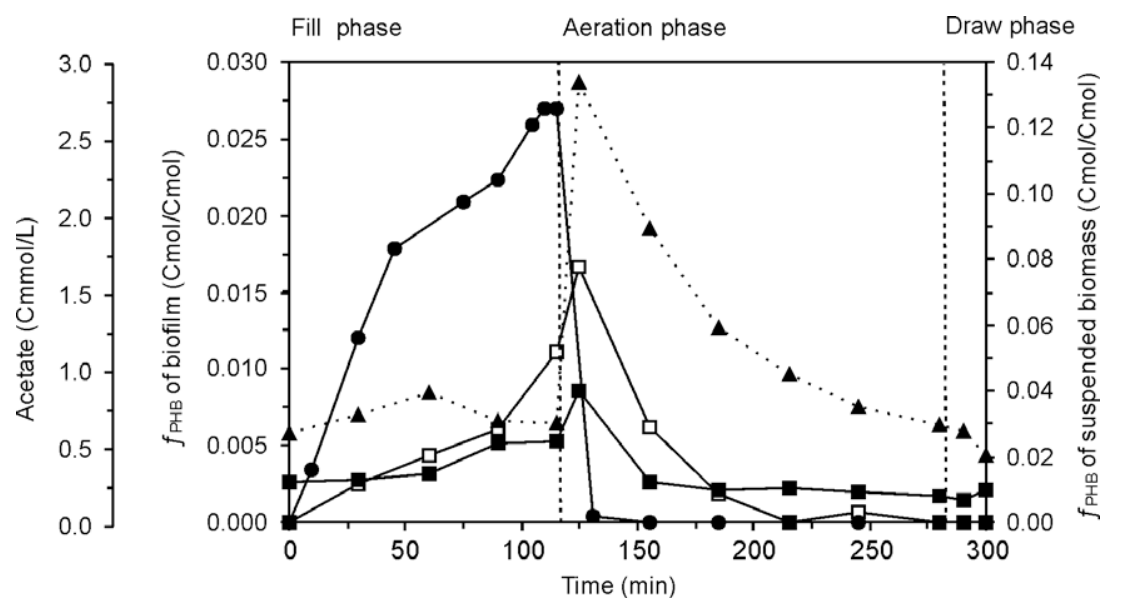

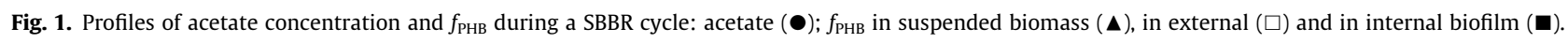

suspended biomass. This result might be explained by the fact that $f_{\text {PHB }}$ depends simultaneously on two factors: (i) the acetate availability which, in the present work, is dependent on mass transfer limitation from the bulk liquid to the cells, and (ii) the fraction of heterotrophs in the biomass.

In a SBBR there is a considerable difference in residence time between suspended and fixed biomass (biofilm) due to the regular exchange of liquid phase. Therefore, it can be assumed that at comparatively long hydraulic retention times (e.g. $14 \mathrm{~h}$ for SBBR), the fast growing heterotrophic microorganisms (with a reciprocal maximum specific growth rate, $1 / \mu_{\max }=5 \mathrm{~h}$, smaller than the selected hydraulic retention time) grow mainly in suspension with favorable mass transfer conditions while the slow growing nitrifiers $\left(1 / \mu_{\max }=25 \mathrm{~h}\right)$ form biofilms as a strategy to prevent their washout from the reactor (van Benthum et al., 1997).

The quantification of PHB in the biomass has allowed to complement the balance of carbon during the operation cycle illustrated in Fig. 1. It was estimated that the carbon removed from the bulk liquid during the fill phase was used to biomass growth (15\%), as a source of energy (25\%) and stored as PHB (25\%). The remaining $35 \%$ was probably removed by other mechanisms such as conversion to intracellular intermediary composts of a low molecular weight or storage as another PHA, besides PHB. This assumption is supported by Dionisi et al. (2001), who found experimental evidence of the accumulation of a high fraction of carbon (30\%) as composts of a low molecular weight, and by studies, which reported the synthesis of other PHA, besides PHB, from acetate as a source of carbon: Lemos et al. (1998) has observed the production of PHB and PHV (polyhydroxyvalerate) from acetate, in which PHB is the predominant polymer (75\%). Satoh et al. (1992) have verified that, from the total quantity of acetate consumed, around $87 \%$ was transformed into PHB, $11 \%$ into PHV, $2 \%$ into $\mathrm{PH} 2 \mathrm{MB}$ (polyhydroxy-2-metilbutyrate) and the remaining $1 \%$ into PH2MV (polyhydroxy-2-metilvalerate). Unfortunately, within the current work there was no possibility to identify and quantify other PHA than PHB in the biomass.

The acetate present at the beginning of the aeration phase is quickly converted and stored in the biomass as PHB (Fig. 1). After acetate depletion, a part of the PHB (70\%) is consumed as a source of carbon and energy, while the rest is stored in the biomass (30\%). According to the reactions' stoichiometry, the organic carbon transformed into PHB during the aeration phase would be sufficient to denitrify the entire nitrate previously produced. However, this did not occur probably due to the high concentration of oxygen dissolved in the liquid. Instead the PHB was consumed in the production of biomass and in energy needs.
As a summary there are two relevant mechanisms of carbon removal in the SBBR, which depend on the operation phase of the reactor: (1) the use of the acetate simultaneously with both, the growth of biomass and metabolism of PHB storage (fill phase); and (2) the direct storage as PHB which is later on used as a source of carbon and energy in the growth of biomass (aeration phase).

\subsection{Nitrogen removal in the $S B B R$}

Fig. 2 depicts profiles of nitrogen ions, acetate and oxygen, during a typical SBBR cycle. During the fill phase, acetate and ammonium concentrations increased due to influent addition. The nitrate left over from the previous cycle was completely denitrified with acetate, via nitrite.

In the subsequent aeration phase, the acetate was rapidly removed from the liquid phase. Time profiles of ammonium, nitrite and nitrate concentration in the aeration phase showed the typical behaviour of nitrification reactions, via nitrite formation and subsequent oxidation to nitrate. A nitrogen balance of this phase showed that $66 \%$ (15.4 mmol) of ammonium supplied was oxidized to nitrate with the remainder being used for biomass growth.

\subsection{Kinetics of PHB degradation}

The PHB degradation rate in activated sludge was described by Beun et al. (2002) through a first order kinetics using a wide range of $f_{\mathrm{PHB}}$ values obtained under anoxic and aerobic conditions. Similarly, the PHB degradation rate in the SBBR may be related to a first order kinetics (Fig. 3) suggesting that it depend on the PHB content of the biomass. Rate constants of $0.011 \mathrm{~min}^{-1}$ for suspended biomass and $0.024 \mathrm{~min}^{-1}$ for the biofilm were obtained. The rate constant of the biomass in suspension in this research is higher than the rate constants of $0.0025 \mathrm{~min}^{-1}$ and $0.0033 \mathrm{~min}^{-1}$ mentioned in other studies (Beun et al., 2002; Carta et al., 2001; Third et al., 2003) for biological sludge. This difference may be explained by the necessary acclimatization of the biomass to cyclic fluctuations in substrate concentration: literature data was obtained with activated sludge from treatment plants, which had merely been acclimatized to cyclic fluctuations during a limited time. However, in the present work the SBBR had been in operation for about one year and the biomass was fully adapted to its operation conditions. Regarding the rate constant for the biofilm, there is no information available in literature. The rate constant in the biofilm is around two times higher than in suspended biomass (Fig. 3). It may be assumed that biofilm and suspended biomass have developed diverging response strategies due to different environmental 


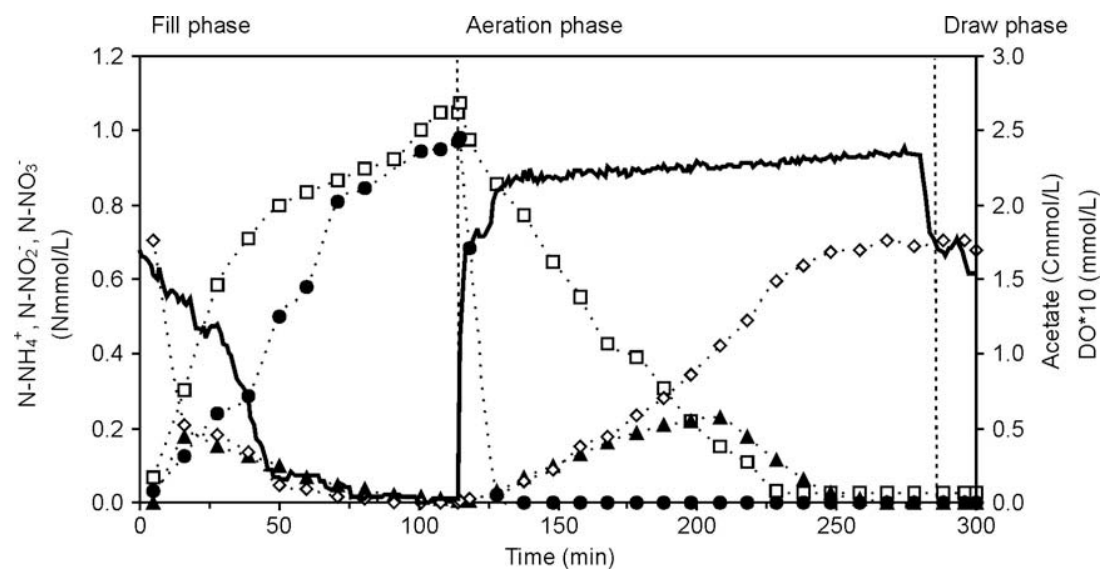

Fig. 2. Acetate $(\bullet)$, oxygen (-), ammonium $(\square)$, nitrite $(\boldsymbol{\Delta})$ and nitrate $(\diamond)$ profiles during a representative SBBR cycle.

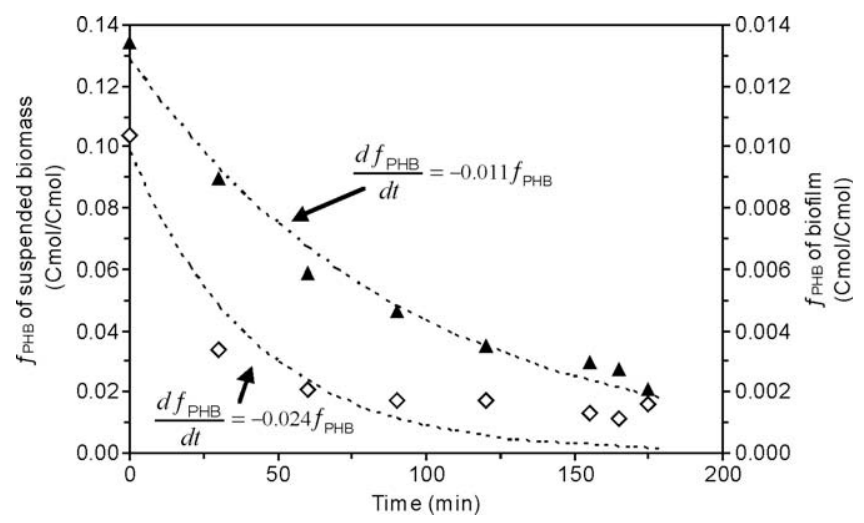

Fig. 3. Kinetics of the degradation of PHB in the biomass during the aeration phase: $(\boldsymbol{\Delta}) f_{\mathrm{PHB}}$ in suspended biomass; $(\diamond) f_{\mathrm{PHB}}$ in the biofilm.

conditions (substrate concentrations, bacterial population composition and others).

Maximum specific PHB degradation rates were calculated through the initial slope of the curves $f_{\mathrm{PHB}}$ versus time for suspended biomass and biofilm. The biomass in suspension presented a maximum specific PHB degradation rate $(0.090 \mathrm{Cmol} / \mathrm{Cmol} \mathrm{h})$ that is around five times higher than the one of biofilm $(0.012 \mathrm{Cmol} / \mathrm{Cmol} \mathrm{h})$. This result was expected because $f_{\mathrm{PHB}}$ in suspended biomass was at least ten times higher than the corresponding value in the biofilm.

\subsection{Composition of the nitrifying population within the biofilm}

FISH analysis was utilized to qualitatively evaluate the biofilm composition with respect to nitrifying microbial population. In situ hybridization of the biofilm with the Nso1225 probe indicated that the ammonia-oxidizing microorganisms belong to the $\beta$-Proteobacteria subclass. No signals were obtained with the Nit3 probe, while the Nitrospira-specific Ntspa662 probe yielded a bright signal, thus the presence of Nitrobacter species can be excluded, so that the nitrite oxidation was exclusively catalysed by Nitrospira bacteria, which confirms the recently discovered importance of this bacteria in nitrite oxidation for numerous environments (Daims et al., 2001; Nogueira et al., 2002; Nogueira and Melo, 2006).

The aggregates formed within the biofilm by ammonia-oxidizing microorganisms and by Nitrospira are found on the same level and close to each other. This association has also been detected in other studies in various environmental samples (Daims et al., 2001; Nogueira et al., 2002, 2005).

\section{Conclusions}

The consumption of acetate and its storage as PHB is mostly carried out by the biomass in suspension. Its maximum fraction of PHB accumulation was $0.13 \mathrm{Cmol} / \mathrm{Cmol}$, around ten times higher than the value accumulated in the biofilm. Although the biomass in suspension represented only $20 \%$ of the total biomass present in the reactor, $79 \%$ of the total PHB formed was stored in the biomass in suspension. This result is due to the lower mass limitations of the biomass in suspension in comparison with the biofilm.

The degradation of PHB in the biomass in suspension and in the biofilm follows a first order degradation kinetics with respective constant rates of $0.011 \mathrm{~min}^{-1}$ and $0.024 \mathrm{~min}^{-1}$. So far, no study has presented any information on the accumulation and degradation of PHB in biofilms.

\section{Acknowledgements}

This work was supported by FCT (PRAXIS XXI BD/19687/99) and FEDER, Program POCI 2010 (POCI/AMB/61155/2004).

\section{References}

Beun, J.J., Paletta, F., van Loosdrecht, M.C.M., Heijnen, J.J., 2000a. Stoichiometry and kinetics of poly-hydroxybutyrate metabolism in aerobic, slow growing, activated sludge cultures. Biotechnol. Bioeng. 67, 379-389.

Beun, J.J., Verhoef, E.V., van Loosdrecht, M.C.M., Heijnen, J.J., 2000b. Stoichiometry and kinetics of poly-hydroxybutyrate metabolism under denitrifying conditions in the activated sludge cultures. Biotechnol. Bioeng. 68, 496-507.

Beun, J.J., Heijnen, J.J., van Loosdrecht, M.C.M., 2001. N-removal in a granular sludge sequencing batch airlift reactor. Biotechnol. Bioeng. 75, 82-92.

Beun, J.J., Dircks, K., van Loosdrecht, M.C.M., Heijnen, J.J., 2002. Polyhydroxybutyrate metabolism in dynamically fed mixed microbial cultures. Water Res. 36, 1167-1180.

Brito, A.G., Peixoto, J., Oliveira, J.M., Oliveira, J.O., Costa, C., Nogueira, R., Rodrigues, A., 2006. Brewery and winery wastewater treatment: some focal points of design and operation. In: Oreopoulou, V., Winfred, R. (Eds.), Utilization of ByProducts and Treatment of Waste in the Food Industry. ISEKI Series, vol. 3. Springer, New York, pp. 109-131.

Carta, F., Beun, J.J., van Loosdrecht, M.C.M., Heijnen, J.J., 2001. Simultaneous storage and degradation of PHB and glycogen in activated sludge cultures. Water Res. 35, 2693-2701.

Daims, H., Nielsen, J.L., Nielsen, P.H., Schleifer, K.H., Wagner, M., 2001. In situ characterization of Nitrospira-like nitrite-oxidizing bacteria active in wastewater treatment plants. Appl. Environ. Microbiol. 67, 5273-5284.

Dionisi, D., Majone, M., Ramadori, R., Beccari, M., 2001. The storage of acetate under anoxic conditions. Water Res. 35, 2661-2668.

Henze, M., Harremoës, P., Jansen, J.l.C., Arvin, E., 1995. Wastewater treatment biological and chemical processes. Springer-Verlag, Berlin, Heidelberg, New York.

Karahan, O., Orhon, D., van Loosdrecht, M.C.M., 2008. Simultaneous storage and utilization of polyhydroxyalkanoates and glycogen under aerobic conditions. Water Sci. Technol. 58, 945-951.

Krishna, C., van Loosdrecht, M.C.M., 1999. Effect of temperature on storage polymers and settleability of activated sludge. Water Res. 33, 2374-2382. 
Lemos, P.C., Viana, C., Salgueiro, E.N., Ramos, A.M., Crespo, J.P.S.G., Reis, M.A.M., 1998. Effect of carbon source on the formation of polyhydroxyalkanoates (PHA) by a phosphate-accumulating mixed culture. Enzyme Microbiol. Technol. 22, 662-671.

Majone, M., Dircks, K., Beun, J.J., 1999. Aerobic storage under dynamic conditions in activated sludge processes: the state of the art. Water Sci. Technol. 39, 61-73.

Manz, W., Amann, R., Ludwig, W., Wagner, M., Schleifer, K.H., 1992. Phylogenetic oligonucleotide probes for the major subclasses of Proteobacteria: problems and solutions. Syst. Appl. Microbiol. 15, 593-600.

Mobarry, B.K., Wagner, M., Urbain, V., Rittmann, B.E., Stahl, D.A., 1996. Phylogenetic probes for analysing abundance and spatial organization of nitrifying bacteria. Appl. Environ. Microbiol. 62, 2156-2162.

Nogueira, R., Melo, L., 2006. Competition between Nitrospira and Nitrobacter spp. in nitrite-oxidizing bioreactors. Biotechnol. Bioeng. 95, 169-175.

Nogueira, R., Melo, L.F., Purkhold, U., Wuertz, S., Wagner, M., 2002. Microbial population dynamics versus nitrification performance in biofilm reactors: effects of hydraulic retention time and the presence of organic carbon. Water Res. 36, 469-481.

Nogueira, R., Elenter, D., Brito, A., Melo, L.F., Wagner, M., Morgenroth, E., 2005 Evaluating heterotrophic growth in a nitrifying biofilm reactor using fluorescence in situ hybridization and mathematical modeling. Water Sci. Technol. 52, 135-141.

Reichert, P., 1994. AQUASIM - a tool for simulation and data analysis of aquatic systems. Water Sci. Technol. 30, 21-30.
Rodrigues, A.C., Brito, A.G., Melo, L.F., 2001. Post treatment of a brewery wastewater using a sequencing batch reactor. Water Environ. Res. 73, 45-51.

Salehizadeh, H., van Loosdrecht, M.C.M., 2004. Production of polyhydroxyalkanoates by mixed cultures: recent trends and biotechnological importance. Biotechnol. Adv. 22, 261-279.

Satoh, H., Mino, T., Matsuo, T., 1992. Uptake of organic substrates and accumulation of polyhydroxyalkanoates linked with glycolysis of intracellular carbohydrates under anaerobic conditions in the biological excess phosphate removal process. Water Sci. Technol. 26, 933-942.

Smolders, G.J.F., van der Meij, J., van Loosdrecht, M.C.M., Heijnen, J.J., 1994 Stoichiometric model of the aerobic metabolism of the biological phosphorus removal process. Biotechnol. Bioeng. 44, 837-848.

Third, K.A., Newland, M., Cord-Ruwisch, R., 2003. The effect of dissolved oxygen on PHB accumulation in activated sludge cultures. Biotechnol. Bioeng. 82, 238250.

van Benthum, W.A.J., van Loosdrecht, M.C.M., Heijnen, J.J., 1997. Control of heterotrophic layer formation on nitrifying biofilms in a biofilm airlift suspension reactor. Biotechnol. Bioeng. 53, 397-405.

Vishniac, W., Santer, M., 1957. The Thiobacilli. Bact. Rev. 21, 195-213.

Wagner, M., Rath, G., Koops, H.P., Flood, J., Amann, R., 1996. In situ analysis of nitrifying bacteria in sewage treatment plants. Water Sci. Technol. 34, 237-244.

Wilderer, P.A., Irvine, R.L., Goronszy, M.C., 2001. Sequencing batch reactor technology (Scientific and Technical Report No. 10), IWA Publishing. 